\title{
Transcription factors gene expression in chronic rhinosinusitis with and without nasal polyps
}

\author{
Tanja Kosak Soklic ${ }^{1,2}$, Matija Rijavec ${ }^{3}$, Mira Silar $^{3}$, Ana Koren ${ }^{3}$, Izidor Kern ${ }^{3}$, Irena Hocevar- \\ Boltezar ${ }^{1,2}$, Peter Korosec ${ }^{3}$ \\ ${ }^{1}$ Department of Otorhinolaryngology and Head \& Neck Surgery, University Medical Centre Ljubljana, Ljubljana, Slovenia \\ ${ }^{2}$ Faculty of Medicine, University of Ljubljana, Ljubljana, Slovenia \\ ${ }^{3}$ University Clinic of Respiratory and Allergic Diseases Golnik, Golnik, Slovenia
}

Radiol Oncol 2019; 53(3): 323-330.

Received 12 February 2019

Accepted 15 May 2019

Correspondence to: Tanja Kosak Soklic, M.D., M.Sc., Department of Otorhinolaryngology and Head \& Neck Surgery, University Medical Centre Ljubljana, Zaloška 2, SI-1000 Ljubljana, Slovenia. Phone: +386 41603 876; E-mail: tanja.soklic@kclj.si

Disclosure: No potential conflicts of interest were disclosed.

Background. Chronic rhinosinusitis (CRS) current therapeutic approaches still fail in some patients with severe persistent symptoms and recurrences after surgery. We aimed to evaluate the master transcription factors gene expression levels of T cell subtypes in chronic rhinosinusitis with nasal polyps (CRSWNP) and chronic rhinosinusitis without nasal polyps (CRSSNP) that could represent new, up-stream targets for topical DNAzyme treatment.

Patients and methods. Twenty-two newly diagnosed CRS patients (14 CRSWNP and 8 CRSSNP) were prospectively biopsied and examined histopathologically. Gene expression levels of T-box transcription factor (T-bet, TBX21), GATA binding protein 3 (GATA3), Retinoic acid-related orphan receptor C (RORC) and Forkhead box P3 (FOXP3) were analyzed by real-time quantitative polymerase chain reaction (RT-GPCR).

Results. Eosinophilic CRSWNP was characterized by higher level of GATA3 gene expression compared to noneosinophilic CRSWNP, whereas there was no difference in T-bet, RORC and FOXP3 between eosinophilic and noneosinophilic CRSWNP. In CRSSNP, we found simultaneous upregulation of T-bet, GATA3 and RORC gene expression levels in comparison to CRSWNP; meanwhile, there was no difference in FOXP3 gene expression between CRSWNP and CRSSNP.

Conclusions. In eosinophilic CRSWNP, we confirmed the type 2 inflammation by elevated GATA3 gene expression level. In CRSSNP, we unexpectedly found simultaneous upregulation of T-bet and GATA3 that is currently unexplained; however, it might originate from activated CD8+ cells, abundant in nasal mucosa of CRSSNP patients. The elevated RORC in CRSSNP could be part of homeostatic nasal immune response that might be better preserved in CRSSNP patients compared to CRSWNP patients. Further data on transcription factors expression rates in CRS phenotypes are needed.

Key words: chronic rhinosinusitis; nasal polyps; Th1 cells; Th2 cells; Th17 cells; Transcription factors

\section{Introduction}

The estimated prevalence of chronic rhinosinusitis (CRS) is more than $10 \%$ in the European and US adult population. ${ }^{1}$ CRS can be subdivided into chronic rhinosinusitis with nasal polyps (CRSwNP) and chronic rhinosinusitis without nasal polyps (CRSsNP). Histopathologically, CRSwNP can be further classified into eosinophilic CRSwNP (with pronounced eosinophilic mucosal infiltration and type-2 inflammation) and noneosinophilic CRSwNP. ${ }^{2}$

Studies on cytokine profiles and transcription factor expression rates characterized eosinophilic CRSwNP by mucosal eosinophilia, Th2 and type 2 innate cell inflammation., ${ }^{3,4}$ Type 2 inflammation cytokines in CRSwNP are IL-4, IL-5 and IL-13, eosinophilic cationic protein (ECP) or Charcot Leyden Crystal protein.-6 IL-5 is a key mediator in type 2 inflammation, providing survival, maturation and 
activation of eosinophils at the bone marrow and the site of inflammation. ${ }^{7}$ Higher levels of mucosal and/or peripheral blood eosinophils are correlated with poor life quality, asthma comorbidity, recurrences after endoscopic surgery and CRSwNP disease severity, associated with inadequate defence against bacteria and viruses. ${ }^{8,9}$ Additionally, eosinophilic CRSwNP is associated with disrupted epithelial barrier and Staphylococcus aureus presence, which intramucosaly releases enterotoxins (SE). SE are immunogenic superantigens that bind to $\mathrm{T}$ cell receptors with unrestricted antigen specificity to activate $\mathrm{T}$ and $\mathrm{B}$ cells, finally leading to specific SE IgE production. ${ }^{10}$ SE IgE amplify the type 2 inflammation in eosinophilic CRSwNP and are an independent risk factor for asthma comorbidity. ${ }^{9,10}$ Staphylococcus aureus presence in nasal mucosal biofilm was associated with worse postoperative outcome after endoscopic surgery. ${ }^{11}$

Noneosinophilic CRSwNP was characterized by mixed Th1/ Th2/ Th17 pattern. ${ }^{4}$ A flow cytometric study showed a predominant Th1 endotype in CRSwNP in addition to Th2; however, in basal conditions, those Th1 cells were not activated, did not release cytokine IFN $\gamma$ and thus the authors hypothesized that an increased number of Th1 in CRSwNP was not related to inflammation pathogenesis. ${ }^{12}$ Similarly, in our recent flow cytometric study, we found more abundant Th1 cells in CRSwNP compared to CRSsNP; however, we didn't find any impact of Th1 cell count on disease control and speculated that Th1 cells were not important for the pathogenesis in CRSwNP. ${ }^{13}$

CRSsNP was found to have more heterogeneous endotypes, with either Th1, Th2 or Th17 cytokines; furthermore, the remodelling process was not in correlation with CRSsNP endotype. ${ }^{4,9,14}$ Th17 cells can secrete IL-17, IL-22 or IFN- $\gamma$ upon stimulation. ${ }^{15}$ Moreover, in our recent flow cytometric study, we found that Th17 cells in CRSwNP were associated with well-controlled CRSwNP. ${ }^{13}$ Similarly, Th17 were reported to have a potentially protective immune homeostatic role in CRSwNP and to be a part of the normal homeostatic immune response in healthy nasal mucosa by IL-17 production. ${ }^{15}$

Regulatory $\mathrm{T}$ cells (Treg) control the CRS inflammation; the regulatory cells deficiency or dysfunction can lead to exaggerated inflammation; on the other hand, an elevated Treg number might be a sign of an unsuccessful inflammation control by immune system. ${ }^{16}$

Current therapeutic approaches still fail in a portion of patients with severe persistent CRS symptoms and recurrences after surgery. ${ }^{17}$ Future treatment concepts focus on up-stream targets like transcription factors; GATA3 DNAzyme topical therapy attenuated Th2-regulated inflammatory responses in asthma. ${ }^{18}$

Therefore, we decided to evaluate the gene expression of intrinsic cellular, lineage-defining, master transcription factors for effector $\mathrm{T}$ helper lymphocytes (Th) in relation to CRS phenotypes (CRSwNP compared to CRSsNP, eosinophilic CRSwNP compared to noneosinophilic CRSwNP): T-box transcription factor (T-bet, TBX21) for Th1 cells, GATA binding protein 3 (GATA3) for Th2 cells and Retinoic acid-related orphan receptor $C$ (RORC) for Th17 cells. Additionally, we aimed to characterize Forkhead box P3 (FOXP3), the master transcription factor for the regulatory $\mathrm{T}$ cell (Treg) gene expression level to evaluate Treg cell bias in CRS phenotypes.

\section{Patients and methods}

\section{Study subjects}

Twenty-two newly diagnosed, adult CRS patients (14 CRSwNP, 8 CRSsNP) were prospectively included at their first visit at the Department of Otorhinolaryngology and Head \& Neck Surgery, University Medical Centre, Ljubljana, Slovenia. CRS diagnosis was established by symptoms, nasal endoscopy and a 2 or $3 \mathrm{~mm}$ computed tomography (CT) scan of paranasal sinuses. Included patients have never before used intranasal or systemic steroids. We took a biopsy of the middle meatal nasal polyp in CRSwNP patients or uncinate process mucosa in CRSsNP patients. Detailed patient inclusion data are shown in the flowchart in Figure 1 and detailed demographic data are summarized in Table 1. This study was conducted in accordance with the amended Declaration of Helsinki. The study was approved by the Slovenian National Medical Ethics Committee (approval number 34/10/12) and patients gave their written informed consent.

\section{Histopathology}

After sampling, the biopsy specimen was immediately fixed in 10\% neutral-buffered formalin. Each paraffin-embedded specimen was sectioned at 5 micrometers thickness and stained by hematoxylin-eosin. The histopathologic evaluation of nasal biopsy specimens was performed using a structured CRS inflammation report as described by. ${ }^{2}$ On hematoxylin-eosin-stained sections, the specimens were analyzed for eosinophil count per high 
TABLE 1. Demographic features, investigations and histopathological findings

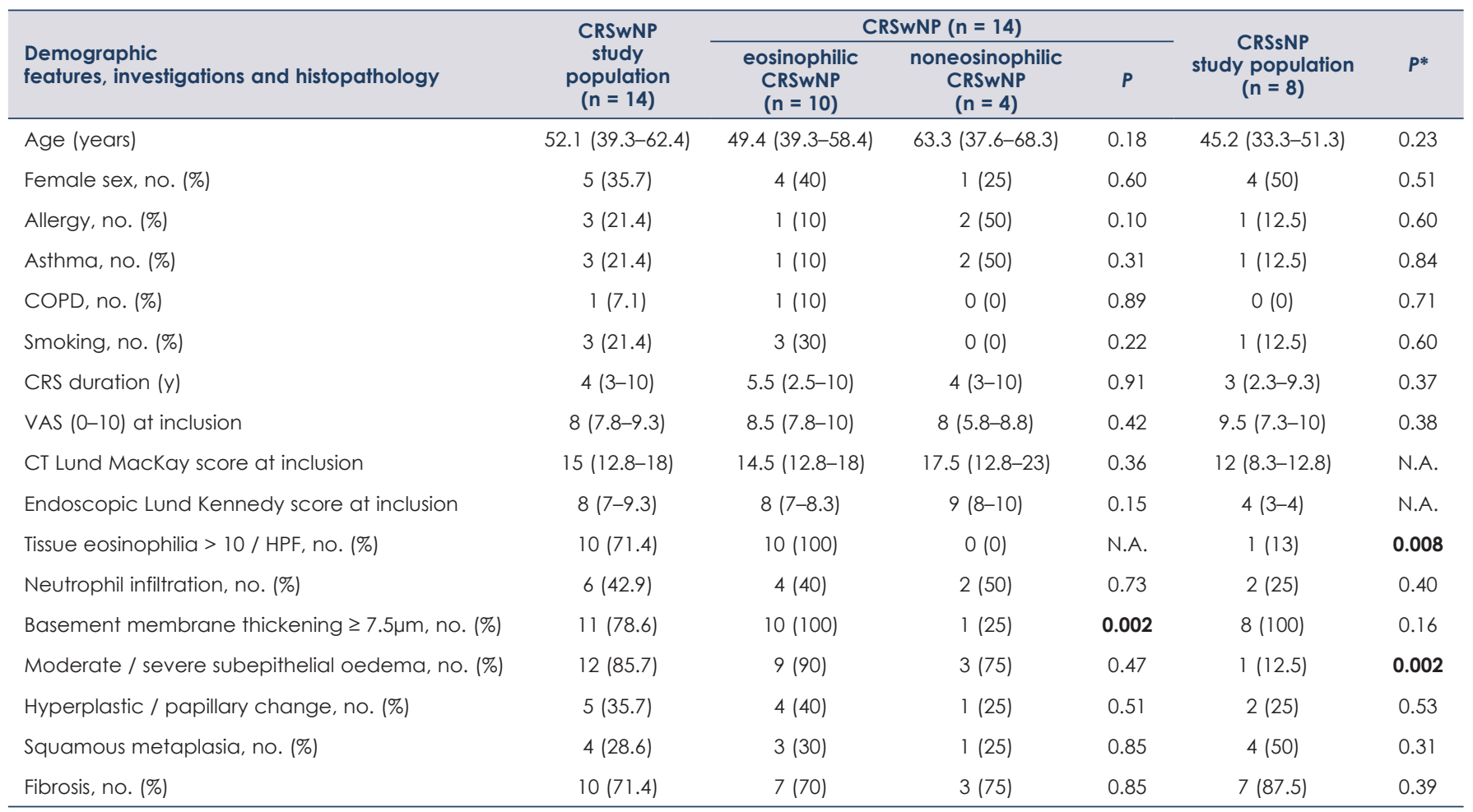

* $P$ refers to the comparison between CRSWNP and CRSSNP; values are expressed as numbers (percentages) or medians (Q1-Q3); $P<0.05$ are boldface; $C R S=$ chronic rhinosinusitis; HPF = high power field; N.A. = not applicable, values are not indicated because these characteristics are the basis for the patient's classification; VAS = visual analogue scale

power field $(\mathrm{HPF})(<5,5-10,>10)$, neutrophilic infiltration, basement membrane thickening $(\geq$ $7.5 \mu \mathrm{m}$ ), subepithelial edema (absent to mild, moderate to severe) and presence of hyperplastic / papillary change, squamous metaplasia and fibrosis.

\section{Tbet (TBX21), GATA3, RORC and FOXP3 gene expression levels}

After sampling, tissue biopsy was stored in RNAlater solution (Qiagen, Hilden, Germany) at $-40^{\circ} \mathrm{C}$. Total RNA was extracted using miRNeasy Mini Kit (Qiagen), according to the manufacturer's instructions, and reverse transcribed to cDNA using the High-capacity cDNA Reverse Transcription Kit (Applied Biosystems, Foster City, CA, USA). RT-qPCR was performed on ABI PRISM 7500 Fast Real-Time PCR System at standard conditions utilizing TaqMan Fast Advanced Master Mix (Applied Biosystems). The Taqman assays T-bet (TBX21) (Hs00203436_m1), GATA3 (Hs00231122_m1), RORC (Hs01076122_m1) and FOXP3 (Hs00203958_m1) were utilized to determine the mRNA expression levels of transcription factors and glyceraldehyde-

\section{CRS patients ( 14 CRSWNP, 8 CRSsNP)}

Diagnosis by CRS symptoms, endoscopic CRS signs and CT CRS signs Not included - if ever used nasal or systemic steroids, if in the last 4 weeks used antibiotics or antihistamines, Aspirin exacerbated respiratory disease, cystic fibros, primary ciliary dyskinesia

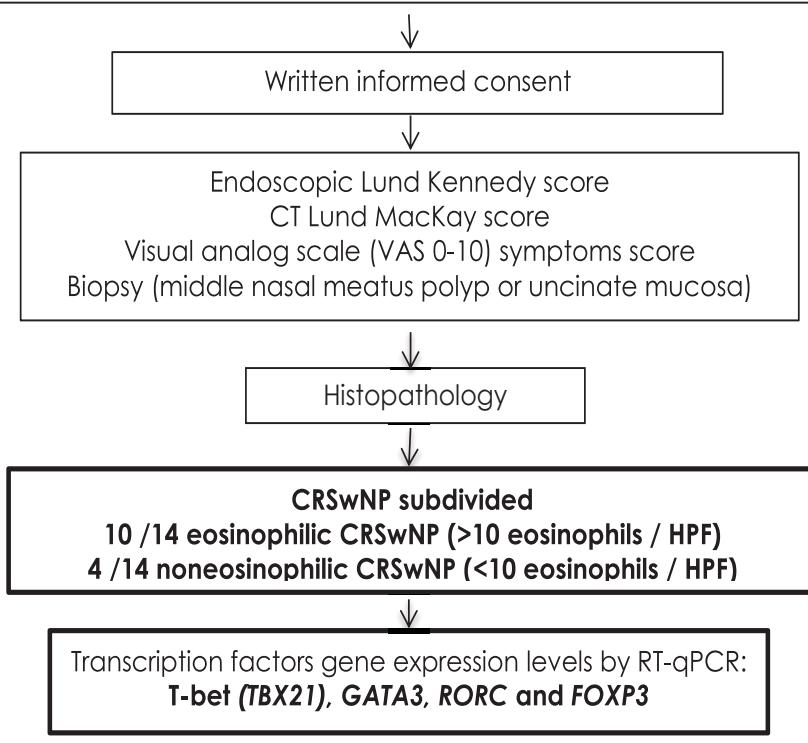

FIGURE 1. Flowchart of the inclusion of the study subjects. 
TABLE 2. T-bet (TBX21), GATA3, RORC and FOXP3 gene expression (relative mRNA levels) in CRS nasal mucosa

\begin{tabular}{|c|c|c|c|c|c|c|}
\hline & \multirow{2}{*}{$\begin{array}{c}\text { CRSwNP } \\
\text { study population } \\
(\mathrm{n}=14)\end{array}$} & \multicolumn{3}{|c|}{$\begin{array}{l}\text { CRSWNP } \\
(n=14)\end{array}$} & \multirow{2}{*}{$\begin{array}{c}\text { CRSsNP } \\
\text { study population } \\
(n=8)\end{array}$} & \multirow[b]{2}{*}{$P^{*}$} \\
\hline & & $\begin{array}{l}\text { eosinophilic } \\
\text { CRSwNP } \\
(n=10)\end{array}$ & $\begin{array}{c}\text { noneosinophilic } \\
\text { CRSwNP } \\
(n=4)\end{array}$ & $P$ & & \\
\hline T-bet & $1.6(0.5-2.4)$ & $2.0(0.5-3.9)$ & $1.1(0.5-2.0)$ & 0.43 & $7.9(4.4-11.8)$ & 0.0003 \\
\hline GATA3 & $0.6(0.3-0.8)$ & $0.7(0.6-1.3)$ & $0.3(0.1-0.4)$ & 0.02 & $4.1(2.3-9.6)$ & 0.0003 \\
\hline RORC & $1.7(0.5-4.0)$ & $1.7(0.5-5.0)$ & $1.3(0.3-3.3)$ & 0.71 & $6.9(3.8-13.3)$ & 0.006 \\
\hline FOXP3 & $1.6(1.2-3.7)$ & $1.6(1.1-3.7)$ & $1.6(1.2-4.5)$ & 0.76 & $3.8(1.0-10.8)$ & 0.73 \\
\hline
\end{tabular}

* $P$ refers to the comparison between CRSWNP and CRSSNP; values are expressed as medians (Q1-Q3); $P<0.05$ are boldface

3-phosphate dehydrogenase (GAPDH; 4333764F) as an endogenous control (all Applied Biosystems). All measurements were performed in triplicate for each sample and relative expression was analyzed using the $\Delta \Delta \mathrm{Ct}$ method. ${ }^{19}$ Briefly, the relative expression of each mRNA was calculated by subtracting the $\mathrm{Ct}$ value of GAPDH from the $\mathrm{Ct}$ value of the gene analyzed to calculate the $\Delta \mathrm{Ct} .{ }^{19}$ Then the relative expression of the sample was calculated using

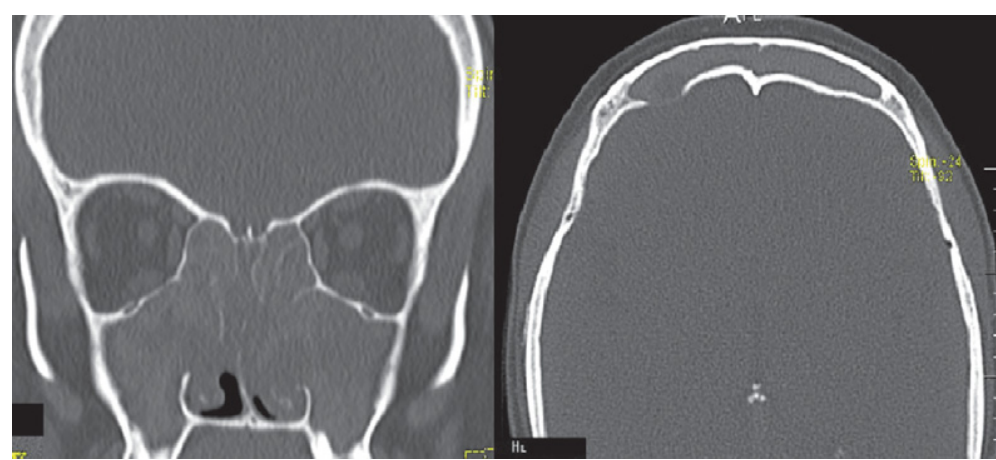

FIGURE 2. A representative CT scan of one CRSWNP patient in frontal and axial plane, CT Lund MacKay score 24.

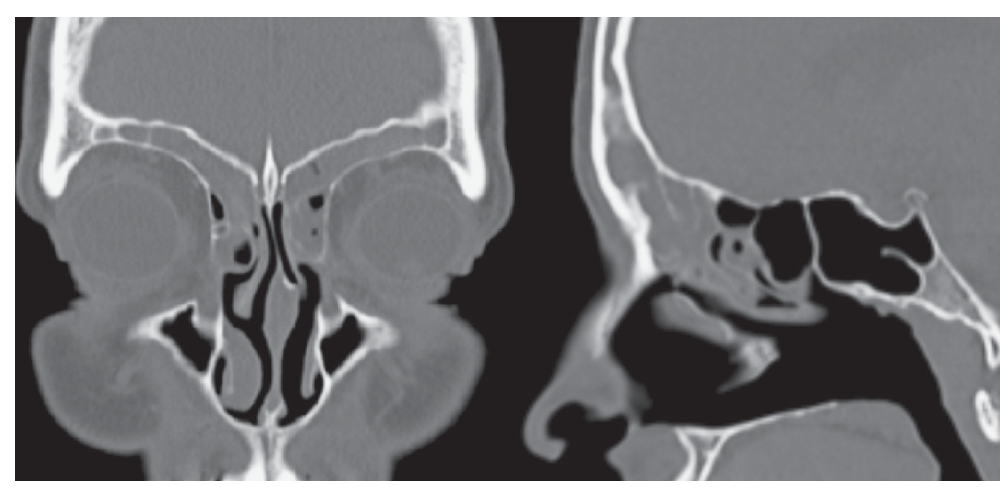

FIGURE 3. A representative CT scan of one CRSsNP patient in frontal view (left) and sagittal view (right), CT Lund MacKay score 8. the formula RQ sample $=2^{-(\Delta \mathrm{Ct} \text { sample- } \Delta \mathrm{Ct} \text { calibrator })}$. Nasal mucosa from the uncinate process of a control subject, 55 years old healthy female without CRS was used as a calibrator.

\section{Statistical analysis}

The data generated in the study were analyzed using GraphPad Prism 6.0 (San Diego, CA, USA). Statistical analysis was performed using the MannWhitney and Chi-square tests as appropriate with 2-tailed $p$. The data are expressed as numbers (percentages) or medians (first quartile (Q1) - third quartile (Q3)). The significance level was set at a $\mathrm{p}$ value of 0.05 .

\section{Results}

\section{Clinical analysis of CRSwNP compared to CRSsNP}

Twenty-two newly diagnosed CRS patients (14 CRSwNP and 8 CRSsNP) were prospectively included in the study. They have not been treated yet and have never used intranasal or systemic steroids. Both groups were comparable in age, sex, smoking, allergy, asthma, chronic obstructive pulmonary disease (COPD) and severity of CRS symptoms on visual analog scale $0-10$. As expected, patients with CRSwNP had higher endoscopic Kennedy Lund scores than patients with CRSsNP. Exact clinical data are summarized in Table 1.

\section{Paranasal sinus CT scan}

In concordance with CRS phenotypes, patients with CRSwNP had higher CT Lund MacKay scores at inclusion than patients with CRSsNP. Exact CT 
scores are summarized in Table 1. Representative CT scans of one CRSwNP and one CRSsNP patient are shown (Figure 2,3).

\section{Histopathological analysis of CRSwNP compared to CRSsNP and eosinophilic CRSWNP compared to noneosinophilic CRSWNP}

Tissue eosinophilia $>10$ per HPF was significantly more frequent $(71 \%)$ in CRSwNP patients compared to CRSsNP patients (13\%); meanwhile, there was no difference in tissue neutrophil infiltration between groups. As expected, moderate to severe subepithelial oedema was more pronounced in CRSwNP patients compared to CRSsNP patients. 10 CRSwNP patients with $>10$ tissue eosinophils per HPF represented the eosinophilic CRSwNP group, the other $4 \mathrm{CRSwNP}$ patients with $<10$ tissue eosinophils per HPF represented the noneosinophilic CRSwNP group. More eosinophilic CRSwNP patients had basement membrane thickening $\geq 7.5 \mu \mathrm{m}$ compared to noneosinophilic CRSwNP patients. There was no difference in hyperplastic or papillary change, squamous metaplasia and fibrosis between groups. Exact histopathological data are summarized in Table 1.

\section{Transcription factors gene expression levels analysis in eosinophilic CRSWNP compared to noneosinophilic CRSWNP patients and in CRSWNP compared to CRSsNP}

GATA3 gene expression level was significantly upregulated in eosinophilic CRSwNP compared to noneosinophilic CRSwNP patients (Table 2 and Figure 4B). There was no difference in T-bet, RORC and FOXP3 expression levels between eosinophilic and noneosinophilic CRSwNP patients (Figures $4 \mathrm{~A}, \mathrm{C}, \mathrm{D})$. Effector Th cell master transcription factors T-bet, GATA3 and RORC gene expression levels in nasal mucosal were significantly elevated in CRSsNP compared to CRSwNP patients (Table 2 and Figures 5A, B, C). On the other hand, Treg master transcription factor FOXP3 gene expression level was equalized in CRSwNP and CRSsNP patients (Figure 5D).

\section{Discussion}

In this prospective study, we analyzed histopathological characteristics and master transcription
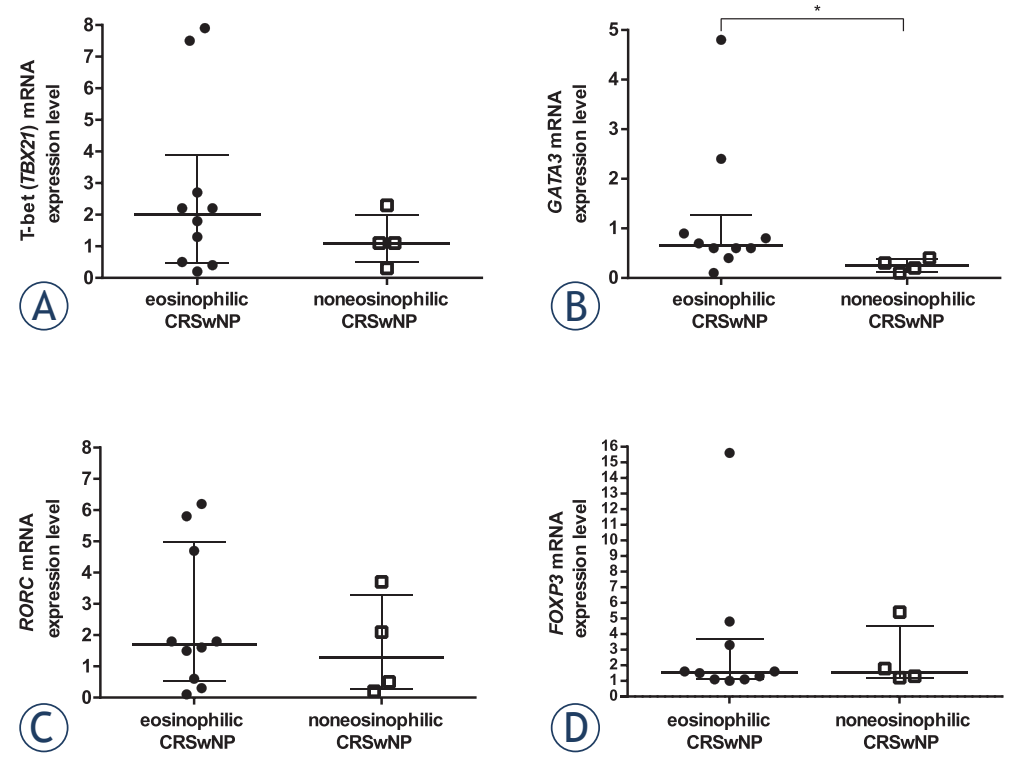

FIGURE 4. Comparison of mRNA expression levels between eosinophilic CRSWNP and noneosinophilic CRSWNP in (A) T-bet (TBX21) mRNA, (B) GATA3 mRNA, (C) RORC mRNA and (D) FOXP3 mRNA expression. ${ }^{*} P<0.05$ by the Mann-Whitney test.
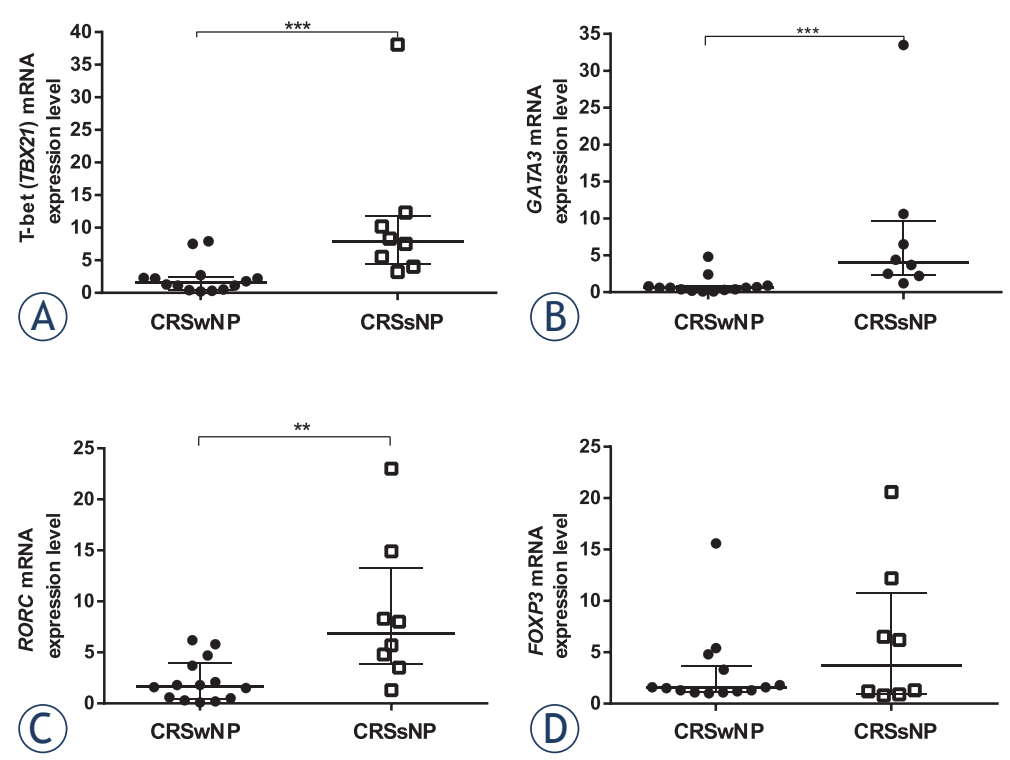

FIGURE 5. Comparison of mRNA expression levels between CRSWNP and CRSSNP in (A) T-bet (TBX21) mRNA, (B) GATA3 mRNA, (C) RORC mRNA and (D) FOXP3 mRNA expression. ${ }^{* P}<0.05,{ }^{* * P}<0.001$, and ${ }^{* * *} \mathrm{P}<0.0001$ by the Mann-Whitney test.

factors gene expression levels of nasal mucosa $\mathrm{T}$ cells in newly diagnosed CRSwNP and CRSsNP patients, who have not been treated yet and have never used intranasal or systemic steroids. 


\section{Mucosal eosinophilia and histopathological differences}

We confirmed previous findings that CRSwNP is characterized by mucosal eosinophilia and pronounced subepithelial oedema. ${ }^{2}$ Additionally, basement membrane thickening $\geq 7.5 \mu \mathrm{m}$ as a sign of remodeling and more severe inflammation was more pronounced in eosinophilic CRSwNP patients with $>10$ tissue eosinophils per HPF compared to noneosinophilic CRSwNP patients with < 10 tissue eosinophils per HPF, in concordance with previous reports. ${ }^{17}$ Tissue eosinophilia in CRSwNP mucosa is known to be associated with type 2 cytokines and inflammation. .17

\section{T-bet transcription factor gene expression}

Surprisingly, we found significantly upregulated T-bet gene expression level in CRSsNP patients compared to CRSwNP. In contrast, one earlier study has reported downregulated T-bet in healthy patients inferior turbinates mucosa and CRSsNP mucosa compared to CRSwNP mucosa ${ }^{6}$, meanwhile, other studies haven't found any difference in T-bet expression between CRSwNP and CRSsNP groups. ${ }^{20,21} \mathrm{~T}$-bet is the master transcription factor of Th1 cells and type 1 innate lymphoid cells (ILC1), it promotes their differentiation, activation and interferon- $\gamma$ (IFN- $\gamma$ ) secretion. ${ }^{22,23}$ In response to IFN- $\gamma$ signaling, T-bet can either activate type 1 inflammation or modulate it in case of exaggerated type 1 response. ${ }^{24}$ Additionally, in effector cytotoxic type CD8+ T cells, T-bet is highly expressed. ${ }^{25}$ Furthermore, in many acute and chronic viral infections, T-bet expression in effector CD8+ cells correlates with infection clearance or improved infection control..$^{26-28}$ In our recent study, we found significantly depleted Th1 and abundant, effector cytotoxic CD8+ cells in CRSsNP nasal mucosa compared to CRSwNP. ${ }^{13}$ We might speculate here that highly upregulated T-bet in CRSsNP patients could originate from expanded effector cytotoxic CD8+ cells in CRSsNP nasal mucosa.

\section{GATA3 transcription factor gene expression}

In this analysis, significantly elevated GATA3 gene expression level in patients with eosinophilic CRSwNP compared to patients with noneosinophilic CRSwNP was found, in concordance with previous reports. ${ }^{21,29}$ GATA3 is the master tran- scription factor of Th2 cells ${ }^{30,31}$ and type 2 innate lymphoid cells (ILC2) ${ }^{32,33}$, enriched in CRS mucosa. ${ }^{3}$ Obviously, upregulated GATA3 expression in the eosinophilic CRSwNP group is related to type 2 (Th2 and ILC-2) inflammation. However, activated effector CD4-CD8- double negative T (DN T) cells can also secrete type 2 cytokines. ${ }^{34,35}$ Importantly, in our recent study, elevated inflammatory DN T cells in the nasal mucosa of patients with uncontrolled CRSwNP were found. The master transcription factor of DN T cells is currently unknown. The impact and contribution of DN T cells to the type 2 inflammation in CRSwNP mucosa needs further investigation.

Unexpectedly, GATA3 gene expression level was significantly higher in patients with CRSsNP compared to patients with CRSwNP, in line with one earlier rtPCR study ${ }^{3}$, meanwhile, in contrast to two immunohistochemic studies. ${ }^{6,20}$ In healthy sinus mucosa, GATA3 expression level was upregulated compared to CRSwNP mucosa, whereas there was no difference in GATA3 between CRSsNP mucosa and healthy sinus mucosa. ${ }^{3}$ Other studies found downregulated GATA3 expression level in healthy patient's inferior turbinates mucosa compared to CRSwNP mucosa ${ }^{6,36}$; however, inferior turbinate mucosa is not the same as sinus mucosa. Interestingly, CD8+ T cells were previously shown to express GATA3 constitutively, upregulate GATA3 upon T cell receptor (TCR) activation and further increase it by IL-4 and IL-2 stimulation. ${ }^{37}$ Moreover, GATA3 expressing and type 2 cytokines producing effector memory CD8+ T cells were confirmed to be elevated in asthma ${ }^{38}$ and tuberculosis infection. ${ }^{39}$ Similarly to high T-bet expression, we might speculate here, that upregulated GATA3 in CRSsNP group could originate from activated effector CD8+ T cells, that were present abundantly in CRSsNP nasal mucosa in our previous study..$^{13}$

\section{$R O R C$ transcription factor gene expression}

We found significantly higher RORC expression in patients with CRSsNP compared to patients with CRSwNP, in line with previous reports. ${ }^{6,20}$ Master transcription factor RORC is expressed by Th1 $17^{40}$ and type 3 innate lymphoid cells (ILC3). ${ }^{41}$ In our previous flow cytometric study, we reported the association of Th17 cells with well-controlled CRSwNP..$^{13}$ The Th17 response was earlier found to be present in the healthy nasal mucosa and therefore, the authors proposed the Th17 cells were a part of normal homeostatic nasal mucosa immune 
response. ${ }^{15}$ Similarly, we could speculate here that upregulated RORC expression level in patients with CRSsNP is part of homeostatic nasal mucosa immune response, that might be better preserved and more functional in CRSsNP mucosa compared to CRSwNP.

\section{FOXP3 transcription factor gene expression level}

FOXP3 expression level was equalized in eosinophilic CRSwNP compared to noneosinophilic CRSwNP as well as in CRSwNP compared to CRSsNP; these observations suggest that regulatory $\mathrm{T}$ cells are not significantly involved in inflammatory bias between CRSwNP and CRSsNP patients. Previously, contradictory results were reported with either no difference in FOXP3 expression levels between CRSwNP and CRSsNP20 or downregulated FOXP3 in CRSwNP compared to CRSsNP. ${ }^{6,42}$ FOXP3 gene expression was found downregulated in CRSwNP patients compared to healthy patients inferior turbinate mucosa. ${ }^{6,36}$ FOXP3 is the master transcription factor for Treg43; in contrast to the other master transcription factors, it has not been identified in ILCs. ${ }^{23}$ Interestingly, some FOXP3+ Treg cells can even co-express another master transcription factor (T-bet, GATA3 or $R O R C)$, however, at much lower levels than corresponding effector Th cells. This way, Tregs may co-localize with corresponding Th effector cells to control their activation ${ }^{23}$; T-bet and FOXP3 co-expression specifically inhibits Th1 and CD8+ T cell activation ${ }^{44}$, GATA3 and FOXP3 co-expression controls type 2 inflammation and also co-modulates Treg function. ${ }^{45}$ Additionally, co-expression of master transcription factors in effector Th cells was noticed in various chronic inflammatory diseases and can play a beneficial or a detrimental role. ${ }^{46-48}$ Moreover, upon in vitro stimulation of CRSwNP mucosa with Staphylococcus aureus enterotoxin (SE), upregulation of Treg was reported; the authors concluded, that Treg cells might be unsuccessful in inflammation control by Th2 activation and Th1 supression. ${ }^{12}$ In the present study, we haven't found any difference in FOXP3 expression levels between eosinophilic and nonesosinophilic CRSwNP patients and therefore, we cannot make any speculations about SE presence and stimulation in the eosinophilic CRSwNP patients mucosa.

Importantly, transcription factor-targeted future treatment strategies might have a positive impact on CRS mucosa by blocking the inflammatory pathway and, on the other hand, a negative impact by targeting co-expression in Tregs and their corresponding inflammation suppression.

\section{Limitations of the study}

This study has some limitations. No control group was included. The groups of patients were relatively small. However, all participants were newly diagnosed and have not been treated with intranasal or systemic steroids yet. Finally, we have only analyzed master transcription factors gene expression levels and not protein expression levels. We plan to expand gene expression investigation in CRS mucosa further to RNA sequence analysis.

To conclude, the type- 2 inflammation was confirmed by elevated GATA3 gene expression level in patients with eosinophilic CRSwNP in comparison to patients with noneosinophilic CRSwNP. The unexpectedly found, simultaneous upregulation of T-bet and GATA3 transcription factors gene expression levels in patients with CRSsNP compared to patients with CRSwNP is currently unexplained; however, it might originate from activated CD8+ cells in CRSsNP nasal mucosa, in concordance with our recent findings of expanded effector cytotoxic CD8+ cells in the mucosa of patients with CRSsNP. ${ }^{13}$ The RORC upregulation in CRSsNP could be part of normal homeostatic nasal mucosa immune response that might be better preserved and more functional in CRSsNP mucosa compared to CRSwNP. In the perspective of future transcription factor-targeted topical treatments development, further data on transcription factors expression rates in CRS phenotypes are needed.

\section{References}

1. DeConde AS, Soler ZM. Chronic rhinosinusitis: epidemiology and burden of disease. Am J Rhinol Allergy 2016; 30: 134-9. doi: 10.2500/ ajra.2016.30.4297

2. Snidvongs K, Lam M, Sacks R, Earls P, Kalish L, Phillips PS, et al. Structured histopathology profiling of chronic rhinosinusitis in routine practice. Int Forum Allergy Rhinol 2012; 2: 376-85. doi: 10.1002/alr.21032

3. Miljkovic D, Bassiouni A, Cooksley C, Ou J, Hauben E, Wormald PJ, et al. Association between Group 2 innate lymphoid cells enrichment, nasal polyps and allergy in chronic rhinosinusitis. Allergy 2014; 69: 1154-61. doi: 10.1111/all.12440

4. Wang X, Zhang N, Bo M, Holtappels G, Zheng M, Lou H, et al. Diversity of $T_{H}$ cytokine profiles in patients with chronic rhinosinusitis: a multicenter study in Europe, Asia, and Oceania. J Allergy Clin Immunol 2016; 138: 1344-53. doi: 10.1016/j.jaci.2016.05.041

5. Van Zele T, Claeys S, Gevaert P, Van Maele G, Holtappels G, Van Cauwenberge $P$, et al. Differentiation of chronic sinus diseases by measurement of inflammatory mediators. Allergy 2006; 61: 1280-9. doi: 10.1111/j.13989995.2006.01225.x

6. Van Bruaene N, Pérez-Novo CA, Basinski TM, Van Zele T, Holtappels G, De Ruyck N, et al. T-cell regulation in chronic paranasal sinus disease. J Allergy Clin Immunol 2008; 121: 1435-41.e3. doi: 10.1016/j.jaci.2008.02.018 
7. Gevaert P, Van Bruaene N, Cattaert T, Van Steen K, Van Zele T, Acke F, et al Mepolizumab, a humanized anti-IL-5 mAb, as a treatment option for severe nasal polyposis. J Allergy Clin Immunol 2011; 128: 989-95.e8. doi: 10.1016/j. jaci.2011.07.056

8. Soler ZM, Sauer D, Mace J, Smith TL. Impact of mucosal eosinophilia and nasal polyposis on quality-of-life outcomes after sinus surgery. Otolaryngol Head Neck Surg 2010; 142: 64-71. doi: 10.1016/j.otohns.2009.10.005

9. Tomassen P, Vandeplas G, Van Zele T, Cardell LO, Arebro J, Olze H, et al. Inflammatory endotypes of chronic rhinosinusitis based on cluster analysis of biomarkers. J Allergy Clin Immunol 2016; 137: 1449-56.e4. doi: 10.1016/j. jaci.2015.12.1324

10. Bachert C, Zhang N, Holtappels G, De Lobel L, van Cauwenberge P, Liu S, et al. Presence of IL-5 protein and IgE antibodies to staphylococcal enterotoxins in nasal polyps is associated with comorbid asthma. J Allergy Clin Immunol 2010; 126: 962-8.e6. doi: 10.1016/j.jaci.2010.07.007

11. Singhal D, Foreman A, Bardy JJ, Wormald PJ. Staphylococcus aureus biofilms. Laryngoscope 2011; 121: 1578-83. doi: 10.1002/lary.21805

12. Derycke L, Eyerich S, Van Crombruggen K, Pérez-Novo C, Holtappels G, Deruyck $\mathrm{N}$, et al. Mixed $\mathrm{T}$ helper cell signatures in chronic rhinosinusitis with and without polyps. PLoS One 2014; 9: e97581. doi: 10.1371/journal. pone. 0097581

13. Soklic TK, Silar M, Rijavec M, Koren A, Kern I, Hocevar-Boltezar I, et al. CD3 + CD4 - CD8 - mucosal T cells are associated with uncontrolled chronic rhinosinusitis with nasal polyps. J Allergy Clin Immunol 2019; 143: 1235-7.e5. doi: 10.1016/j.jaci.2018.10.045

14. Tan BK, Klingler Al, Poposki JA, Stevens WW, Peters AT, Suh LA, et al. Heterogeneous inflammatory patterns in chronic rhinosinusitis without nasal polyps in Chicago, Illinois. J Allergy Clin Immunol 2017; 139: 699-703. e7. doi: 10.1016/j.jaci.2016.06.063

15. Lam EPS, Kariyawasam HH, Rana BMJ, Durham SR, McKenzie ANJ, Powel $\mathrm{N}$, et al. IL-25/IL-33-responsive TH2 cells characterize nasal polyps with a default TH17 signature in nasal mucosa. J Allergy Clin Immunol 2016; 137: 1514-24. doi: 10.1016/j.jaci.2015.10.019

16. Hulse KE, Stevens WW, Tan BK, Schleimer RP. Pathogenesis of nasal polyposis. Clin Exp Allergy 2015; 45: 328-46. doi: 10.1111/cea.12472

17. Akdis CA, Bachert C, Cingi C, Dykewicz MS, Hellings PW, Naclerio RM, et al. Endotypes and phenotypes of chronic rhinosinusitis: a PRACTALL document of the European Academy of Allergy and Clinical Immunology and the American Academy of Allergy, Asthma \& Immunology. J Allergy Clin Immunol 2013; 131: 1479-90. doi: 10.1016/j.jaci.2013.02.036

18. Krug N, Hohlfeld JM, Kirsten AM, Kornmann O, Beeh KM, Kappeler D, et al. Allergen-induced asthmatic responses modified by a GATA3-specific DNAzyme. N Engl J Med 2015; 372: 1987-95. doi: 10.1056/NEJMoa1411776

19. Livak KJ, Schmittgen TD. Analysis of relative gene expression data using realtime quantitative PCR and the 2(-Delta Delta C(T)) method. Methods 2001; 25: 402-8. doi: 10.1006/meth.2001.1262

20. Seif $F$, Ghalehbaghi $B$, Aazami $H$, Mohebbi A, Ahmadi $A$, Falak $R$, et al. Frequency of $\mathrm{CD} 4+$ and $\mathrm{CD} 8+\mathrm{T}$ cells in Iranian chronic rhinosinusitis patients. Allergy Asthma Clin Immunol 2018; 14: 47. doi: 10.1186/s13223-018 0270-9

21. Cao PP, Li HB, Wang BF, Wang SB, You XJ, Cui YH, et al. Distinct immunopathologic characteristics of various types of chronic rhinosinusitis in adult Chinese. J Allergy Clin Immunol 2009; 124: 478-84.e2. doi: 10.1016/j. jaci.2009.05.017

22. Szabo SJ, Kim ST, Costa GL, Zhang X, Fathman CG, Glimcher LH. A nove transcription factor, T-bet, directs Th1 lineage commitment. Cell 2000; 100 655-69.

23. Fang D, Zhu J. Dynamic balance between master transcription factors deter mines the fates and functions of CD4 T cell and innate lymphoid cell subsets. J Exp Med 2017; 214: 1861-76. doi: 10.1084/jem.20170494

24. Iwata S, Mikami Y, Sun HW, Brooks SR, Jankovic D, Hirahara K, et al. The transcription factor T-bet limits amplification of type I IFN transcriptome and circuitry in T helper 1 cells. Immunity 2017; 46: 983-991.e4. doi: 10.1016/j. immuni.2017.05.005

25. Xin A, Masson F, Liao Y, Preston S, Guan T, Gloury R, et al. A molecular threshold for effector $\mathrm{CD} 8+\mathrm{T}$ cell differentiation controlled by transcription factors Blimp-1 and T-bet. Nat Immunol 2016; 17: 422-32. doi: 10.1038/ ni.3410

26. Greenough TC, Straubhaar JR, Kamga L, Weiss ER, Brody RM, McManus $\mathrm{MM}$, et al. A gene expression signature that correlates with $\mathrm{CD} 8+\mathrm{T}$ cell expansion in acute EBV infection. J Immunol 2015; 195: 4185-97. doi: 10.4049/jimmunol.1401513

27. Kurktschiev PD, Raziorrouh B, Schraut W, Backmund M, Wächtler $M$ Wendtner CM, et al. Dysfunctional CD8 + T cells in hepatitis B and C are characterized by a lack of antigen-specific T-bet induction. J Exp Med 2014 211: 2047-59. doi: 10.1084/jem.20131333
28. Smith C, Elhassen D, Gras S, Wynn KK, Dasari V, Tellam J, et al. Endogenous antigen presentation impacts on T-box transcription factor expression and functional maturation of CD8+ T cells. Blood 2012; 120: 3237-45. doi: 10.1182/blood-2012-03-420182

29. Shin SH, Kim YH, Ye MK, Choi SY. Immunopathologic characteristics of nasal polyps in adult Koreans: A single-center study. Am J Rhinol Allergy 2017; 31: 168-73. doi: 10.2500/ajra.2017.31.4423

30. Zheng W, Flavell RA. The transcription factor GATA-3 is necessary and sufficient for Th2 cytokine gene expression in CD4 T cells. Cell 1997; 89: 587-96.

31. Wang L, Wildt KF, Zhu J, Zhang X, Feigenbaum L, Tessarollo L, et al. Distinct functions for the transcription factors GATA-3 and ThPOK during intrathymic differentiation of CD4(+) T cells. Nat Immunol 2008; 9: 1122-30. doi: 10.1038/ni.1647

32. Hoyler T, Klose CSN, Souabni A, Turqueti-Neves A, Pfeifer D, Rawlins EL, et al. The transcription factor GATA-3 controls cell fate and maintenance of type 2 innate lymphoid cells. Immunity 2012; 37: 634-48. doi: 10.1016/j. immuni.2012.06.020

33. Mjösberg J, Bernink J, Golebski K, Karrich JJ, Peters CP, Blom B, et al. The transcription factor GATA3 is essential for the function of human type 2 innate lymphoid cells. Immunity 2012; 37: 649-59. doi: 10.1016/j.immuni.2012.08.015

34. Crispin JC, Tsokos GC. Human TCR- + CD4- CD8- T cells can derive from CD8+ T cells and display an inflammatory effector phenotype. J Immunol 2009; 183: 4675-81. doi: 10.4049/jimmunol.0901533

35. Fischer K, VoelkI S, Heymann J, Przybylski GK, Mondal K, Laumer M, et al. Isolation and characterization of human antigen-specific TCRab+CD4- CD8double-negative regulatory T cells. Blood 2005; 105: 2828-36. doi: 10.1182/ blood-2004-07-2583.Supported

36. Zhang N, Van Zele T, Perez-Novo C, Van Bruaene N, Holtappels G, DeRuyck $\mathrm{N}$, et al. Different types of T-effector cells orchestrate mucosal inflammation in chronic sinus disease. J Allergy Clin Immunol 2008; 122: 961-8. doi: 10.1016/j.jaci.2008.07.008

37. Wang Y, Misumi I, Gu AD, Curtis TA, Su L, Whitmire JK, et al. GATA-3 controls the maintenance and proliferation of T cells downstream of TCR and cytokine signaling. Nat Immunol 2013; 14: 714-22. doi: 10.1038/ni.2623

38. Lee N, You S, Shin MS, Lee WW, Kang KS, Kim SH, et al. IL-6 receptor $\alpha$ defines effector memory CD8 $+T$ cells producing Th2 cytokines and expanding in asthma. Am J Respir Crit Care Med 2014; 190: 1383-94. doi: 10.1164/ rccm.201403-06010C

39. van Meijgaarden KE, Haks MC, Caccamo N, Dieli F, Ottenhoff THM, Joosten $\mathrm{SA}$. Human CD8+ T-cells recognizing peptides from Mycobacterium tuberculosis (Mtb) presented by HLA-E have an unorthodox Th2-like, multifunctional, Mtb inhibitory phenotype and represent a novel human T-cell subset. PLoS Pathog 2015; 11: e1004671. doi: 10.1371/journal.ppat.1004671

40. Ivanov II, McKenzie BS, Zhou L, Tadokoro CE, Lepelley A, Lafaille JJ, et al. The orphan nuclear receptor RORgammat directs the differentiation program of proinflammatory IL-17+ T helper cells. Cell 2006; 126: 1121-33. doi: 10.1016/j.cell.2006.07.035

41. Spits H, Artis D, Colonna M, Diefenbach A, Di Santo JP, Eberl G, et al. Innate lymphoid cells - a proposal for uniform nomenclature. Nat Rev Immunol 2013; 13: 145-9. doi: 10.1038/nri3365

42. Kim YM, Munoz A, Hwang PH, Nadeau KC. Migration of regulatory T cells toward airway epithelial cells is impaired in chronic rhinosinusitis with nasal polyposis. Clin Immunol 2010; 137: 111-21. doi: 10.1016/j.clim.2010.05.013

43. Hori S, Nomura T, Sakaguchi S. Control of regulatory T cell development by the transcription factor Foxp3. Science 2003; 299: 1057-61. doi: 10.1126/ science.1079490

44. Levine AG, Medoza A, Hemmers S, Moltedo B, Niec RE, Schizas M, et al. Stability and function of regulatory $T$ cells expressing the transcription factor T-bet. Nature 2017; 546: 421-5. doi: 10.1038/nature22360

45. Wang Y, Su MA, Wan YY. An essential role of the transcription factor GATA-3 for the function of regulatory T cells. Immunity 2011; 35: 337-48. doi: 10.1016/j.immuni.2011.08.012

46. Kallies A, Good-Jacobson KL. Transcription factor T-bet orchestrates lineage development and function in the immune system. Trends Immunol 2017; 38: 287-97. doi: 10.1016/j.it.2017.02.003

47. Wang YH, Voo KS, Liu B, Chen CY, Uygungil B, Spoede W, et al. A novel subset of $\mathrm{CD} 4+\mathrm{TH} 2$ memory/effector cells that produce inflammatory IL-17 cytokine and promote the exacerbation of chronic allergic asthma. J Exp Med 2010; 207: 2479-91. doi: 10.1084/jem.20101376

48. Peine $M$, Rausch $S$, Helmstetter $C$, Fröhlich $A$, Hegazy AN, Kühl AA, et al. Stable T-bet(+)GATA-3(+) Th1/Th2 hybrid cells arise in vivo, can develop directly from naive precursors, and limit immunopathologic iunflammation. PLOS Biol 2013; 11: e1001633. doi: 10.1371/journal.pbio.1001633 